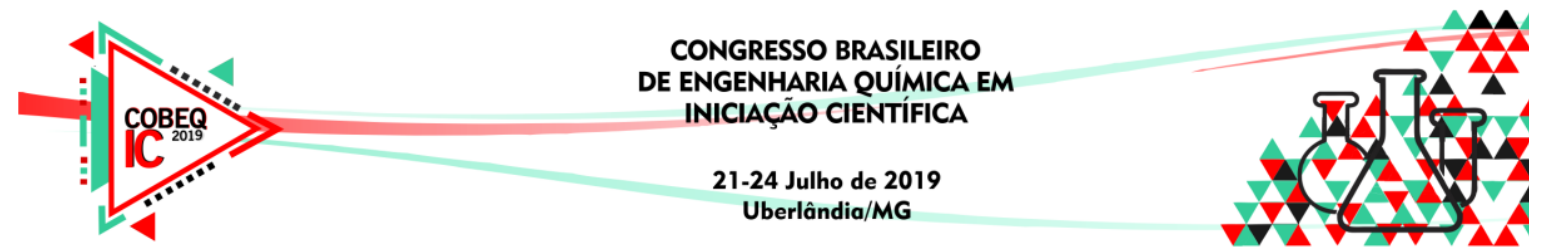

\title{
PRODUÇÃO DE ENERGIA ELÉTRICA POR CÉLULA COMBUSTÍVEL MICROBIOLÓGICA INOCULADA COM SEDIMENTO MARINHO
}

\author{
P. S. LAUX ${ }^{1}$, L. N. COSTA ${ }^{1}$, R. P. BRANCO ${ }^{1}$, T. D. DE SOUZA ${ }^{1}$ e C. S. OGRODOWSKI ${ }^{1}$ \\ ${ }^{1}$ Universidade Federal do Rio Grande, Faculdade de Engenharia Bioquímica \\ E-mail para contato: patricklaux@ hotmail.com
}

\begin{abstract}
RESUMO - As células combustíveis microbiológicas (CCM) surgiram como uma tecnologia promissora que minimiza e substitui os combustíveis fósseis na produção de energia, bem como reduz o impacto ambiental. O objetivo deste trabalho é estudar a geração de energia a partir de uma CCM de câmara dupla inoculada com o sedimento da dragagem do Porto de Rio Grande. A célula é confeccionada com placas de acrílico que constituem o compartimento anódico e catódico, ambos com volumes iguais a 1L, separados por uma membrana catiônica e com a presença de uma placa de grafite que compõem o eletrodo do sistema. $\mathrm{O}$ compartimento anódico é alimentado com substrato $\mathrm{CH}_{3} \mathrm{COOH}$, mantido sob agitação constante, temperatura de $35^{\circ} \mathrm{C}$ e $\mathrm{pH}$ de 7,5 . A voltagem gerada pelo sistema é controlada por um microcontrolador Arduino, responsável pela aquisição e registro dos dados. No startup do experimento foi utilizada uma resistência externa de $1000 \Omega$, a qual foi reduzida a $150 \Omega$ após a realização de uma curva de polarização e determinação da potência máxima atingida no sistema. Utilizando a resistência de $150 \Omega$ atingiu-se uma potência de aproximadamente $188 \mathrm{~mW} / \mathrm{m}^{2}$. Assim, pode-se concluir que as CCM é uma alternativa viável que converte diretamente energia química em eletricidade pelo uso de bactérias exoeletrogênicas.
\end{abstract}

\section{INTRODUÇÃO}

Uma necessidade da sociedade atual é desenvolver tecnologias que, além de minimizar e substituir os combustíveis fósseis, reduzam o impacto ambiental. Assim, em busca de uma alternativa viável para suprir esses anseios, as células combustíveis microbiológicas (CCM) surgiram como uma promissora tecnologia que une a geração de eletricidade com o tratamento de efluentes (TELEKEN et al., 2017; WANG et al., 2013).

A CCM converte substratos orgânicos em eletricidade por intermédio da atividade metabólica dos microrganismos, podendo fazer uso de efluentes industriais e domésticos como combustíveis (RABAEY E VERSTRAETE, 2005). A geração da bioenergia é semelhante ao funcionamento de uma célula combustível química, que produz corrente contínua devido ao fluxo de elétrons que advém da reação de oxirredução (LOGAN, 2008).

De acordo com Logan (2008), os microrganismos responsáveis pela redução da matéria orgânica e a transferência de elétrons produzidos por seu metabolismo celular são denominados exoeletrogênicos. A transferência de elétrons entre os microrganismos e o eletrodo é realizada devido à diferença de potencial elétrico (DDP) existente entre as soluções do ânodo e do cátodo, esta capacidade é designada aos microrganismos que conseguem transferir elétrons para fora 


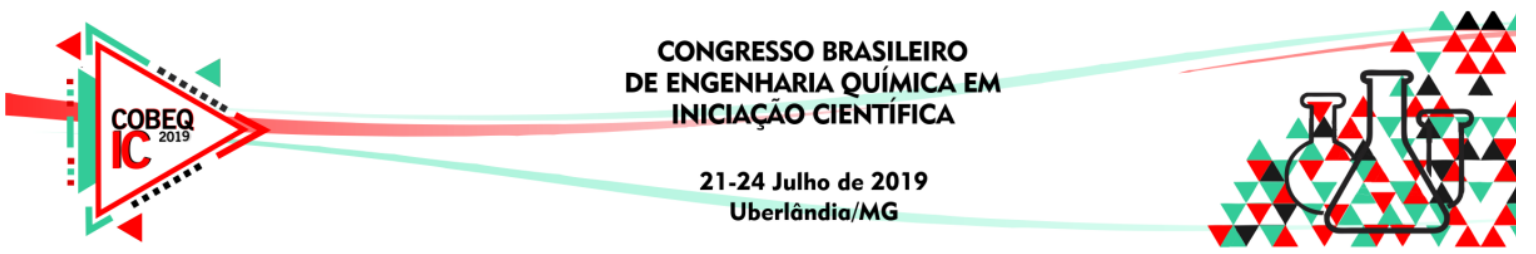

de sua célula, diretamente para um material sólido. A presença destas comunidades no compartimento anódico insolúvel possibilita à formação de um biofilme sobre o eletrodo (LOGAN E RABAEY, 2013; TELEKEN et al., 2017).

Uma CCM pode utilizar substratos orgânicos complexos, incluindo águas residuais domésticas, industriais e agrícolas, como fonte de produção de energia (PANT et al., 2010). Assim, utilizar o material oriundo da dragagem do Porto de Rio Grande como matéria-prima para a produção de eletricidade e bioprodutos passa a ser uma possibilidade promissora, levando em conta que uma grande quantidade de sedimento marinho é retirado a cada processo de dragagem e este resíduo possui alta carga de nutrientes, microrganismos e matéria-orgânica.

Segundo Logan (2008), existe uma ampla variedade de configurações para a construção de uma CCM, sendo uma das formas mais utilizadas a de dois compartimentos (anódico e catódico) separados por uma membrana de permuta iônica e seus eletrodos ligados a uma resistência externa. Assim, buscando desenvolver novas tecnologias para a produção de energia elétrica utilizando uma fonte renovável, o objetivo deste trabalho é estudar a geração de energia a partir de uma célula combustível microbiológica de câmara dupla inoculada com o sedimento do estuário da Lagoa dos Patos.

\section{OBJETIVO}

Avaliar a viabilidade do uso de células combustíveis microbiológicas para a produção de energia elétrica limpa e tratamento dos efluentes do processo de dragagem da Porto de Rio Grande.

\section{MATERIAIS E MÉTODOS}

\subsection{Célula Combustível Microbiológica}

A CCM é confeccionada com placas de acrílico com um volume total de $2 \mathrm{~L}$, sendo $50 \%$ dedicados ao ânodo $(1 \mathrm{~L})$ e $50 \%$ destinados ao cátodo $(1 \mathrm{~L})$. Estes compartimentos são separados por uma membrana catiônica (CMI-7000S - Membranas International Inc.). O compartimento anódico permanece sob agitação constante de $500 \mathrm{rpm}$ por meio de um impelidor. A CCM é mantida em câmara termostatizada a $35^{\circ} \mathrm{C}$ e pH do compartimento anódico ajustado entre 6,8 e 7,5.

A CCM é inoculada com sedimento do estuário da Lagoa dos Patos coletado na coordenada $31^{\circ} 58^{\prime} 25^{\prime}$ 'S $/ 52^{\circ} 02^{\prime} 24^{\prime}$ 'O. O volume do compartimento anódico é inoculado com $70 \%$ de sedimento e o restante com meio de cultivo composto por $\mathrm{NaHCO}_{3}(2,5 \mathrm{~g} / \mathrm{L})$, $\mathrm{CaCl}_{2} \cdot 2 \mathrm{H}_{2} \mathrm{O} \quad(0,1 \mathrm{~g} / \mathrm{L}), \quad \mathrm{KCl} \quad(0,1 \mathrm{~g} / \mathrm{L}), \quad \mathrm{NH}_{4} \mathrm{Cl} \quad(1,5 \mathrm{~g} / \mathrm{L}), \mathrm{NaH}_{4} \mathrm{PO}_{4} \cdot \mathrm{H}_{2} \mathrm{O} \quad(0,6 \mathrm{~g} / \mathrm{L})$, $\mathrm{Na}_{2} \mathrm{HPO}_{4} \cdot 12 \mathrm{H}_{2} \mathrm{O}(1,87 \mathrm{~g} / \mathrm{L}), \mathrm{NaCl}(0,1 \mathrm{~g} / \mathrm{L}), \mathrm{MgCl}_{2} \cdot 6 \mathrm{H}_{2} \mathrm{O}(0,1 \mathrm{~g} / \mathrm{L}), \mathrm{MgSO}_{4} .7 \mathrm{H}_{2} \mathrm{O}(0,1 \mathrm{~g} / \mathrm{L})$, $\mathrm{MnCl}_{2} .4 \mathrm{H}_{2} \mathrm{O}(0,005 \mathrm{~g} / \mathrm{L}), \mathrm{NaMoO}_{4} \cdot 2 \mathrm{H}_{2} \mathrm{O}(0,001 \mathrm{~g} / \mathrm{L})$, extrato de levedura $(0,05 \mathrm{~g} / \mathrm{L})$ e água destilada (DE SÁ et al., 2017). Como fonte de energia e carbono, utiliza-se $\mathrm{CH}_{3} \mathrm{COOH}$ na concentração de $10 \mathrm{~g} / \mathrm{L}$.

O compartimento catódico do reator é preenchido com uma solução de ferricianeto de potássio $\left(\mathrm{K}_{3} \mathrm{Fe}(\mathrm{CN})_{6}\right) 50 \mathrm{mM}$, constituindo o aceptor final de elétrons.

O modo de alimentação do reator é com reciclo total de células, e esta é realizada diariamente para renovação do efluente anódico de acordo com o seguinte procedimento: remove-se 0,3 L do efluente do reator e assim, separa-se os sólidos em suspensão no efluente do reator por centrifugação (modelo Hitachi CR22 GIII) a 18800 g; após esta etapa os sólidos 


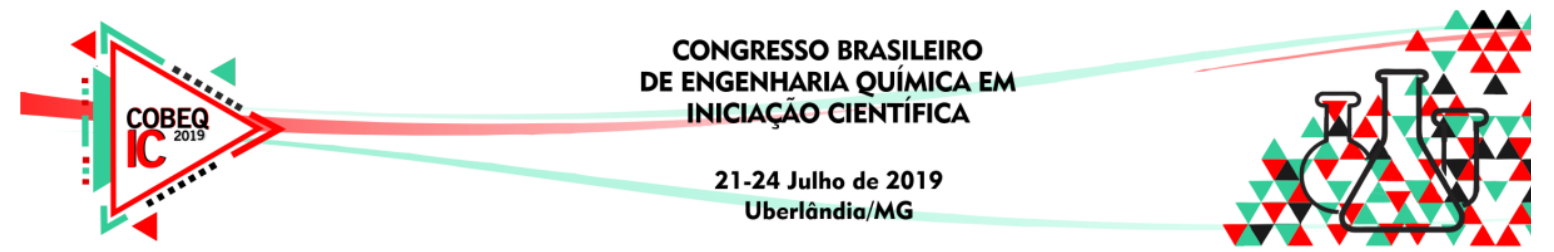

separados são ressuspensos em $0,3 \mathrm{~L}$ de meio de cultivo com $10 \mathrm{~g} / \mathrm{L}$ de fonte de carbono. Após o ajuste do pH dessa suspensão, essa mistura é alimentada ao reator.

\subsection{Aquisição dos Dados}

Durante todo o período de realização do experimento, verifica-se a diferença de potencial elétrico (ddp) gerada pelo sistema por meio de um micro controlador Arduino, ao qual é calculada de acordo com a Equação 1, onde $\mathrm{V}$ é a diferença de potencial elétrico medida em volt $(\mathrm{V}), \mathrm{R}$ é a resistência elétrica em ohm $(\Omega)$ e I a corrente elétrica em ampère $(\mathrm{A})$.

$$
V=R * I
$$

Após estabilização da diferença de potencial elétrico produzido no reator, realizou-se uma curva de polarização para determinar com qual resistência externa ela apresenta densidade de potência máxima, calculada através da Equação 2, onde $\mathrm{P}$ é densidade de potência em $\mathrm{W} / \mathrm{m}^{2}$ e A é a área do eletrodo anódico em metro quadrado $\left(\mathrm{m}^{2}\right)$. Na construção de uma curva de polarização em uma célula eletroquímica aplicam-se diferentes valores de resistores conhecidos e realiza-se a leitura da diferença de potencial elétrico (ddp) gerada entre o ânodo e o cátodo para cada uma das resistências aplicadas. A representação da corrente elétrica em função da ddp é chamada de curva de polarização.

$$
P=\frac{V * I}{A}
$$

\section{RESULTADOS E DISCUSSÃO}

A CCM foi inoculada com sedimento marinho e após seis dias do start up, nas condições estabelecidas, observou-se a primeira medida de ddp, porém sua estabilização levou aproximadamente 20 dias para ocorrer, chegando a valores de ddp de até $0,72 \mathrm{~V}$, com resistência externa de $1000 \Omega$.

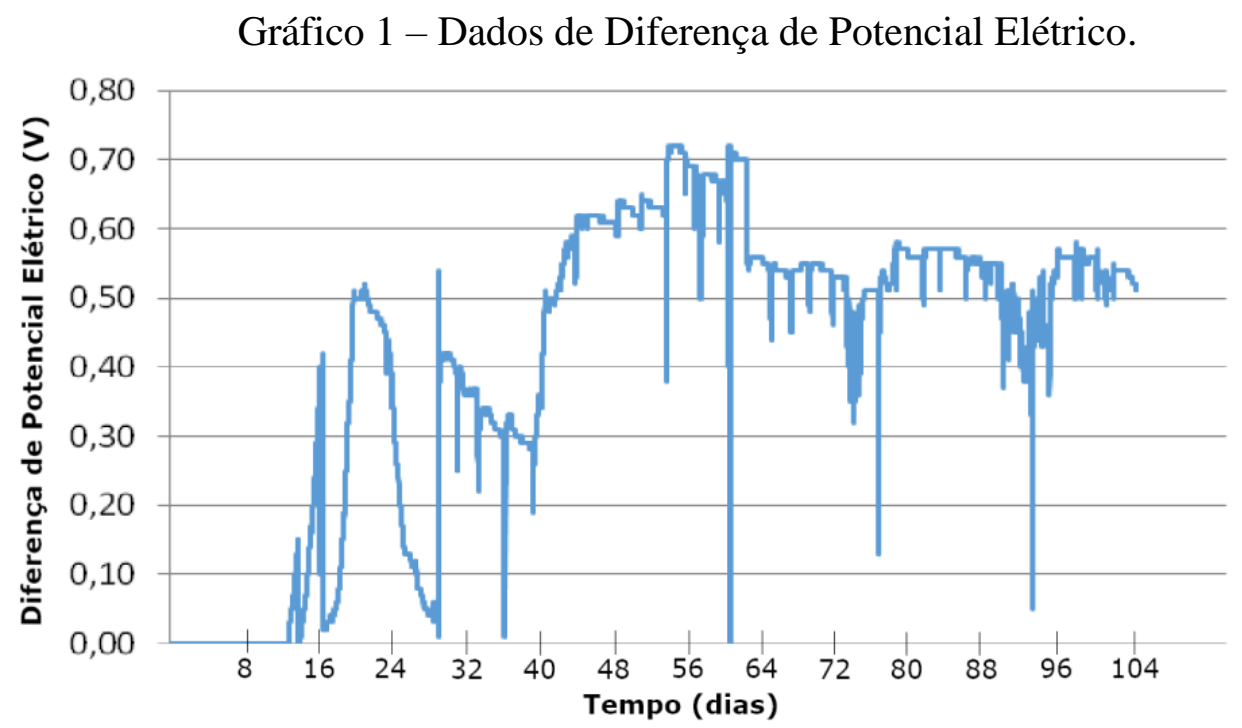




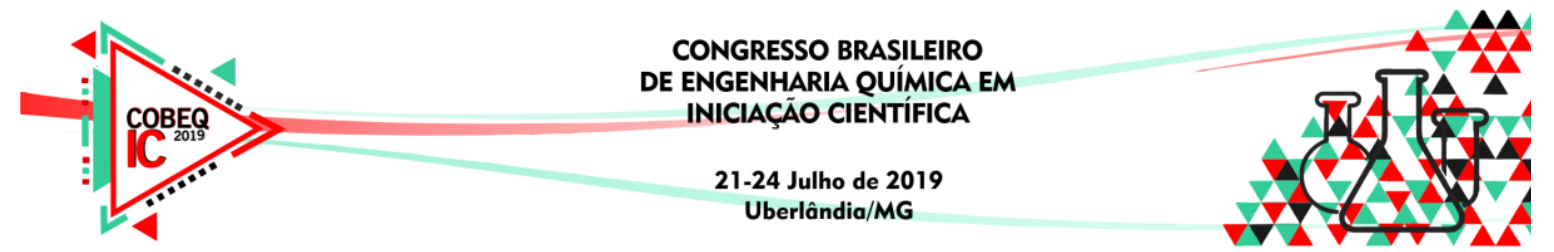

Com a CCM estabilizada após aproximadamente 30 dias de experimento, realizou-se uma curva de polarização e determinou-se que a célula atingiu a densidade de potência máxima de $128 \mathrm{~mW} / \mathrm{m}^{2}$ com a resistência externa de $150 \Omega$, conforme observa-se no Gráfico 2 . Levando em consideração este resultado, reduziu-se a resistência externa do experimento de $1000 \Omega$ para $150 \Omega$. Mesquita (2016), ao utilizar uma CCM com volume de $20 \mathrm{~mL}$ em cada compartimento e inoculada também com o sedimento marinho, atingiu uma densidade de potência máxima de $255 \mathrm{~mW} / \mathrm{m}^{2}$ com resistência externa de $180 \Omega$. Ao relacionar este valor de densidade de potência ao obtido no trabalho em questão, ao qual atingiu-se $237 \mathrm{~mW} / \mathrm{m}^{2}$ com a resistência externa de $150 \Omega$, conclui-se que este resultado é satisfatório já que não teve uma diferença significativa na potência com a diminuição da resistência e utilizar uma resistência externa de menor valor é mais vantajoso, pois esta influencia diretamente na corrente gerada e no desempenho da CCM, ou seja, quando se diminui a resistência externa tem-se um aumento significativo da corrente.

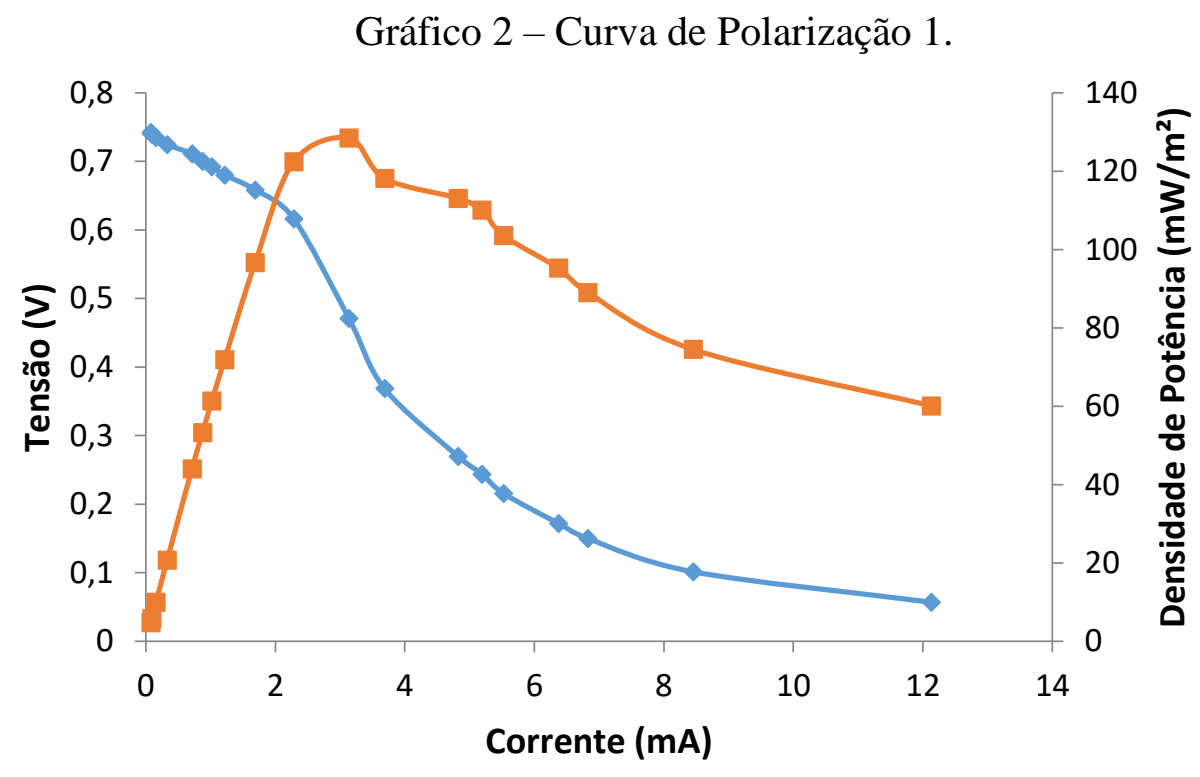

Após estabilização da célula com a resistência externa de $150 \Omega$, realizou-se uma nova curva de polarização para determinação da densidade de potência máxima atingida pelo experimento. Como pode-se observar no Gráfico 3 e confirmando os fundamentos teóricos, a densidade de potência máxima da célula aumentou com a diminuição da resistência externa para $150 \Omega$, obtendo um valor de $335 \mathrm{~mW} / \mathrm{m}^{2}$. 


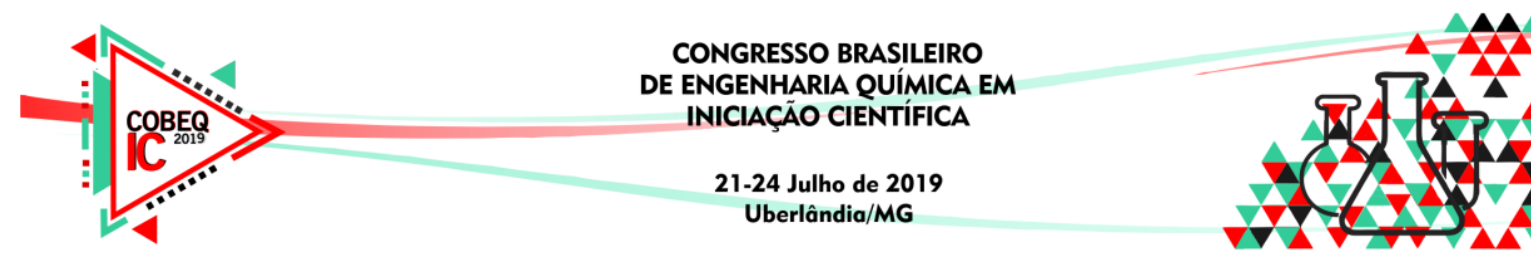

Gráfico 3 - Curva de Polarização 2.

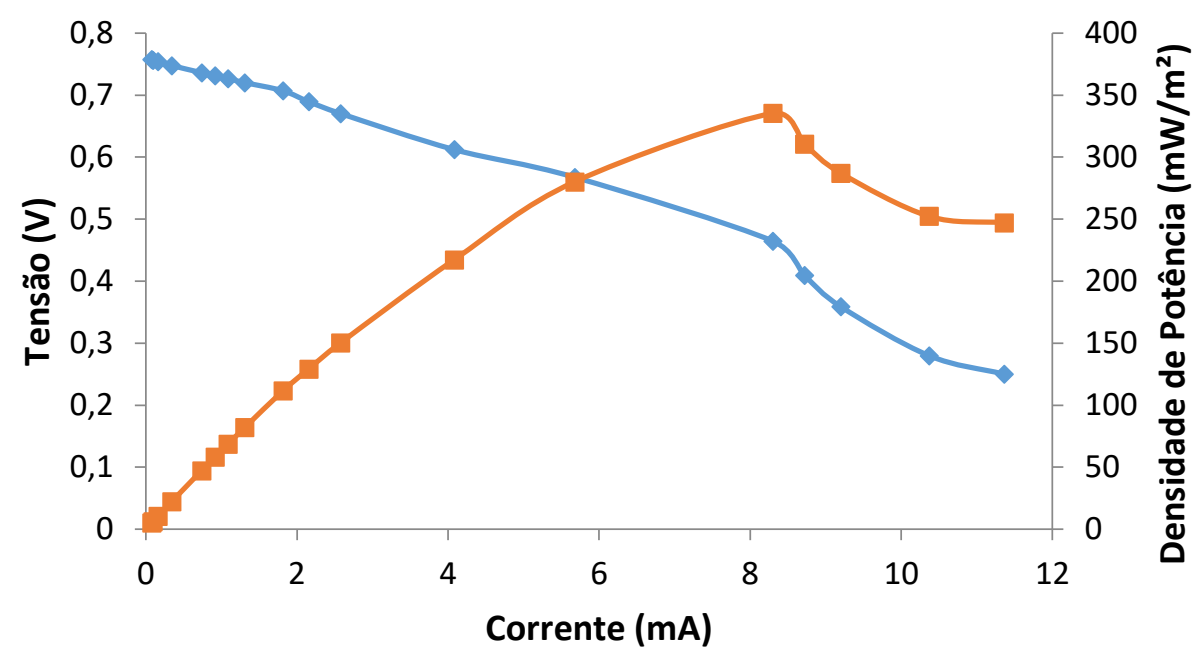

Observa-se nos gráficos 2 e 3, com curva de polarização e de densidade de potência, que a linha em azul representa a curva de polarização e linha em vermelho a curva de densidade de potência.

A Tabela 1 apresenta os principais dados de diferença de potencial elétrico e densidade de potência calculada no decorrer do experimento, e observa-se que a diferença nos resultados de ddp não são expressivos quando modifica-se a resistência externa, porém a densidade de potência atingida é muito maior quando diminuiu-se a resistência externa de $1000 \Omega$ para 150 $\Omega$.

Tabela 1- Dados de Diferença de Potencial Elétrico e Densidade de Potência.

\begin{tabular}{cccc}
\hline & Data & DDP $(\mathrm{V})$ & $\mathrm{P}\left(\mathrm{mW} / \mathrm{m}^{2}\right)$ \\
\hline Start up $1000 \Omega$ & $10 / 04 / 2018$ & 0,00 & 0 \\
\hline Primeira medida $1000 \Omega$ & $15 / 04 / 2018$ & 0,01 & 0,87 \\
\hline Maior medida $1000 \Omega$ & $04 / 05 / 2018$ & 0,72 & 45 \\
\hline Curva de Polarização $150 \Omega$ & $07 / 05 / 2018$ & 0,47 & 128 \\
\hline Maior medida $150 \Omega$ & $13 / 08 / 2018$ & 0,64 & 237 \\
\hline
\end{tabular}

\section{CONCLUSÃO}

Com o aperfeiçoamento das células combustíveis microbiológicas, conclui-se que elas podem ser um bom substituinte para os métodos tradicionais de produção de energia, já que convertem diretamente energia química em eletricidade utilizando fontes renováveis, diminuindo assim o impacto ambiental. Considerando os resultados apresentados, a CCM com volume de $1 \mathrm{~L}$ de compartimento anódico utilizando uma resistência externa de $150 \Omega$ e sendo alimentada com reciclo total de células atingiu densidade de potência máxima de $237 \mathrm{~mW} / \mathrm{m}^{2}$. 


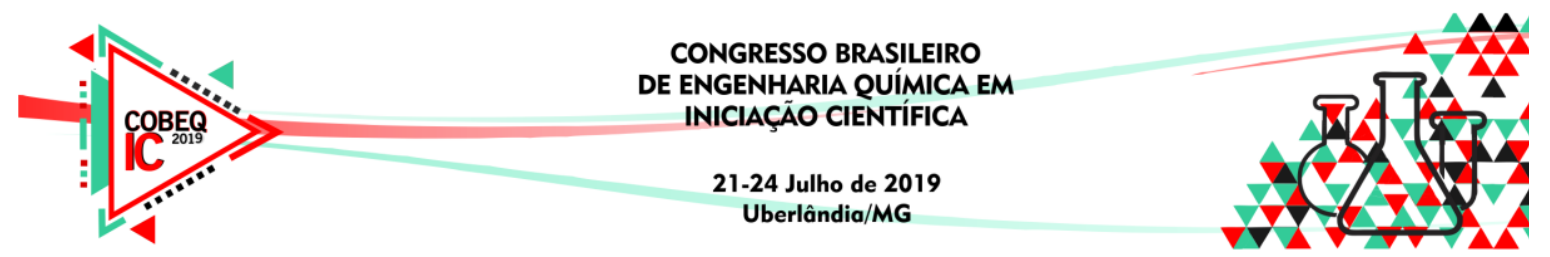

\section{REFERÊNCIAS}

DE SÁ et al. Anode air exposure during microbial fuel cell operation inoculated with marine sediment. Journal of Environmental Chemical Engineering, v. 5, p. 1821-1827, mar. 2017.

LOGAN, B. E. Microbial fuel cells, Wiley-Interscience Microbial fuel cells. New Jersey: John Wiley \& Sons, Inc., Hoboken, 2008.

LOGAN, B. E.; RABAEY, K. Conversion of wastes into bioelectricity and chemicals by using microbial electrochemical technologies. Science, v. 337, p. 686-690, ago, 2013.

MESQUITA, D. Produção de Energia Elétrica em Célula Combustível Microbiológica com Sedimento de Dragagem do Porto de Rio Grande. 2016. Dissertação (Mestrado em Engenharia Química) - Curso de Pós-graduação em Engenharia Química, Universidade Federal do Rio Grande, Rio Grande, 2016.

PANT et al, Review of the substrates used in microbial fuel cells (MFCs) for sustainable energy production. Bioresource Technology, v. 101, p. 1533-1543, mar. 2010.

RABAEY, K.; VERSTRAETE, W. Microbial fuel cells: novel biotechnology for energy generation. Trends in Biotechnology. n. 23, p. 291-298, jun. 2005.

TELEKEN et al. Mathematical Modeling of the Electric Current Generation in a Microbial Fuel Cell Inoculated with Marine Sediment. Journal of Chemical Engineering, v. 34, n. 01, p. 211-225, jan./mar. 2017.

WANG et al. Power production from different types of sewage sludge using microbial fuel cells: A comparative study with energetic and microbiological perspectives. Journal of Power Sources, v. 235, p. 280-288, ago. 2013. 